\title{
Molecular biology of brown adipose tissue
}

By Daniel Ricouier, Centre de Recherche sur la Nutrition, Centre National de la Recherche Scientifique, 9 rue Jules Hetzel - 92190 Meudon-Bellevue, France

Interest in the biology of brown adipose tissue (BAT) has moved from the field of cold adaptation and cellular bioenergetics to the field of nutrition and obesity in recent years. This is mainly due to studies on BAT of 'cafeteria-fed' or obese rodents (Rothwell \& Stock, 1979; Himms-Hagen, 1985; Trayhurn, 1986). In fact most studies on BAT have been focused on direct or indirect assay of the uncoupling protein (UCP) of brown adipocyte mitochondria.

The main emphasis of the present paper is on the use of molecular biology in BAT. Such an approach has been currently developed for UCP, but could be extended to other components that are essential to BAT activity.

\section{The tools of molecular biology}

Research in molecular biology has developed considerably in recent years. Currently, most biochemical and physiological questions have benefited from the utilization of molecular biology. Development of molecular biology is the result of different fundamental investigations. Progress in genetics of phages and bacterial resistance to antibiotics have set phage and plasmid DNA as vectors, and also led to the key discovery of restriction endonucleases. Molecular virologists have discovered reverse transcriptase (EC 2.7.7.49) at the same time. This enzyme offered the inconceivable possibility of obtaining DNA from mRNA. It is now possible to insert any DNA in vectors and construct recombinant DNA libraries. A particular genomic or complementary DNA can then be cloned.

Table 1 lists several questions which require the use of molecular biology. Gene expression results in mRNA production and protein synthesis. mRNA can be detected by 'Northern blot' or 'dot blot' experiments in which the mRNA is detected by appropriate genomic or cDNA probe. Elucidation of the mechanism of control of gene activity is difficult, and represents a major challenge to biological research. The initiation rate of gene transcription can be assayed by run-on transcription in isolated nuclei. The site of transcription can be determined using primer extension and S1 nuclease (EC

\section{Table 1. Tools of molecular biology}

\section{Questions}

Gene expression

Gene control

Transcription

cis-Acting element

trans-Acting regulatory factors

Protein structure

Primary structure

Secondary and tertiary structures

Protein activity (for example, UCP)

Nucleotide binding site

$\mathrm{H}^{+}$translocation

\section{Strategy}

Northern analysis immunodetection

Run-on transcription, primer extension, S1 mapping . . .

Gene isolation, cell transfection . . .

Footprinting . . .

cDNA sequencing

Immunology . . .

Photochemistry, site-directed mutagenesis . . . 
3.1.30.1) mapping experiments. Determination of cis-acting elements (promoter, enhancer) requires transfection of cells or transgenic animals. Methods useful to identify trans-acting regulatory factors are under development. Sequencing of isolated cDNA is used to determine primary structure of proteins and predict secondary structure. Finally, expression of cDNA in heterologous system and site-directed mutagenesis can be used to identify amino acid residues involved in catalytic or regulatory activity of proteins.

\section{Molecular biology of uncoupling protein}

UCP is a component unique to BAT mitochondria. It is a proton carrier, and its synthesis is inducible and controlled by sympathetic factors. These features made UCP a good candidate for molecular cloning. This cloning has been achieved in three laboratories. Full-length cDNA of rat UCP (Bouillaud et al. 1985; Ridley et al. 1986) and partial cDNA of mouse UCP (Jacobsson et al. 1985) were isolated first. Following the isolation of rat UCP CDNA, we plan to isolate the UCP gene and molecular probes specific for other species. This strategy is depicted in Fig. 1.

The initial step was the construction of a cDNA library from poly $\left(\mathrm{A}^{+}\right) \mathrm{RNA}$ of cold-exposed rats. Rat UCP CDNAs were isolated from this library, using differential hybridization and hybrid-selected translation of mRNA combined with immunoprecipitation (Bouillaud et al. 1985). The identity of UCP cDNA was also further confirmed by DNA sequencing (Bouillaud et al. 1986). Rat UCP cDNA was then used to screen rat and human genomic libraries and isolate phages carrying rat (Bouillaud et al. 1988a) or human (Bouillaud et al. 1988b; Cassard et al. 1988) UCP gene. Rat UCP cDNA was used once more to analyse ovine and bovine genomic libraries. Finally, bovine and human genomic probes were used to screen a cDNA library constructed from poly $\left(\mathrm{A}^{+}\right) \mathrm{RNA}$ of

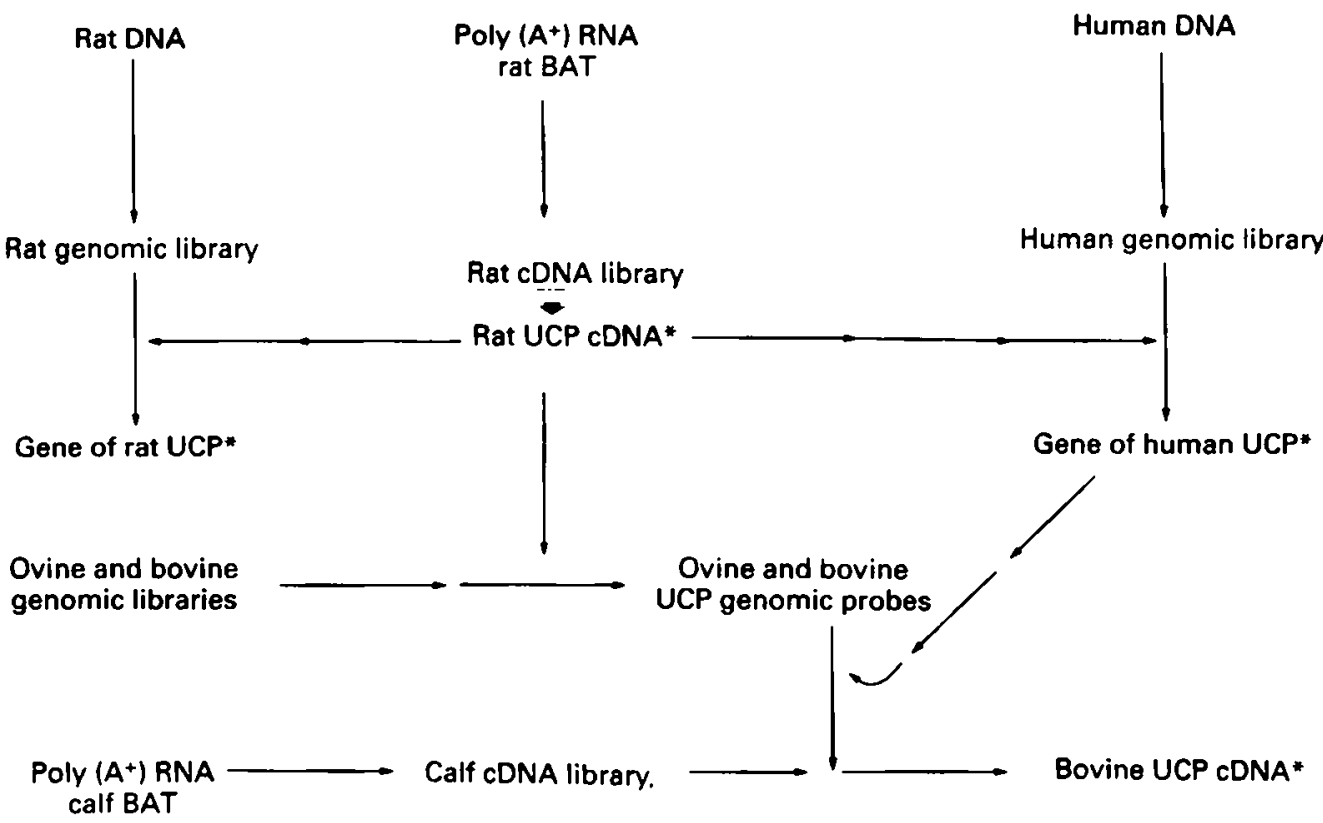

Fig. 1. Strategy of molecular cloning of the uncoupling protein (UCP). Arrows indicate the different steps. - Initial key step. *The different cDNA or genomic fragments isolated. 
perirenal BAT from newborn calf. A bovine UCP CDNA was thus obtained (Casteilla et al. $1989 a, b)$.

These various probes were used to study UCP mRNA, UCP gene expression and UCP sequence in several species. Table 2 summarizes prominent findings. UCP mRNA could never be detected in non-brown-fat cells (Bouillaud et al. 1985; Jacobsson et al. 1986). In rodents UCP has two mRNA (Bouillaud et al. 1985; Jacobsson et al. 1985; Ridley et al. 1986), while in man, cattle and sheep it has only one (Bouillaud et al. 1988b; Casteilla et al. 1988a). UCP mRNA level is rapidly and strongly induced in rodents exposed to cold (Ricquier et al. 1984, 1986; Jacobsson et al. 1986) or during refeeding (O. Champigny and D. Ricquier, unpublished results). Induction of UCP mRNA could be mimicked by injection of $\beta$-adrenoceptor agonist (Jacobsson et al. 1986; Ricquier et al. 1986). Run-on transcription experiments in nuclei isolated from rat BAT have demonstrated that the UCP gene is strongly and rapidly controlled at the level of transcription following the arrival of noradrenaline at the surface of brown adipocytes (Ricquier et al. 1986). Interestingly, in the same study it was observed that UCP gene transcription was strongly impaired in obese ( $f a / f a$ ) rats. However, this apparent defect could be improved in obese animals dosed with a $\beta$-adrenoceptor agonist. These findings, together with analysis of the UCP gene structure (Cassard et al. 1988), revealed that the defect in obese animals is not at the level of the UCP gene itself, but is located in the central nervous system. In sheep and cattle, Casteilla et al. (1989a) have observed that at birth almost all adipose depots contain high concentrations of UCP mRNA, and thus are BAT. Surprisingly, this mRNA disappears in the first days of life, and BAT depots seem to be converted into white adipose tissue.

DNA-derived amino acid sequences of rat, bovine and human UCP were obtained (Bouillaud et al. 1986; Ridley et al. 1986; Bouillaud et al. 1988b; Cassard et al. 1988; Casteilla et al. 1989b). These sequences are highly homologous to the sequence determined for purified hamster UCP by Aquila et al. (1985). Interestingly, these different studies revealed significant homology between UCP and mitochondrial ADP-ATP (Aquila et al. 1982) and phosphate carriers (Runswick et al. 1987), and suggested a common ancestral géne for these components.

More recently, sequencing of the complete rat UCP gene was achieved by Bouillaud et al. (1988a). A detailed study of its organization and regulation is in progress.

\section{Table 2. Use of molecular biology in research on uncoupling protein}

Strategy

Northem analysis

Run-on transcription

DNA sequencing

Gene isolation

\section{Results}

UCP mRNA is specific for brown fat. $1.5 \mathrm{~kb}$ mRNA in rodents, $1.8 \mathrm{~kb}$ mRNA in cattle, sheep and man.

UCP mRNA level is increased in brown fat activated by cold exposure or refeeding.

UCP gene is regulated at the transcriptional level. Transcription can be activated by $\beta$-agonist drug. Transcription is impaired in obese ( $f a / f a)$ rat.

Determination of amino acid sequence of UCP in rat, calf and man. UCP is homologous to other mitochondrial carriers.

Rat and human UCP gene have been isolated.

UCP gene transcription site has been identified.

Rat UCP gene has been entirely sequenced (six exons).

UCP has one gene. 
Table 3. Molecular biology of brown adipose tissue: future research

\author{
Components \\ Lipoprotein lipase (EC 3.1.1.34) \\ Atypical $\beta$-adrenoceptor \\ Mitochondrial proteins \\ Type II thyroxine 5'-deiodinase (EC 3.8.1.4)
}

Function

Fatty acid import

Binding of noradrenaline

Oxidation, mitochondriogenesis

$\mathrm{T}_{4} \rightarrow \mathrm{T}_{3}$

Function in BAT activity and adipocyte differentiation

$\mathrm{T}_{4}$, thyroxine; $\mathrm{T}_{3}$, triiodothyronine; $\mathrm{BAT}$, brown adipose tissue.

\section{Molecular biology of other components: future research}

Besides research on UCP, which has to be continued, it has been pointed out that BAT activity is strongly dependent on other proteins such as lipoprotein lipase (EC 3.1.1.34), atypical $\beta$-adrenoceptor (Arch et al. 1984), mitochondrial proteins and type II thyroxine 5'-deiodinase (EC 3.8.1.4) (Silva \& Larsen, 1983). Assuredly, a molecular biological study of these components will be beneficial (Table 3 ).

Lipoprotein lipase activity is strongly induced during activation of BAT (Carneheim et al. 1984) in such a manner that BAT is a good model for the study of the regulation of the lipoprotein lipase gene. The existence of an atypical $\beta$-adrenoceptor in brown adipocytes is a matter of dispute. Cloning of this receptor and comparison with adrenoreceptors recently cloned by others will certainly close the debate. It could also be helpful in synthesis of agonist drugs highly specific for brown adipocyte activation. Brown adipocytes have a high capacity of mitochondriogenesis, and could thus be used for cloning of various mitochondrial proteins. Finally, Silva \& Larsen (1983) have pointed out that rodent BAT contains a high level of type II thyroxine 5'-deiodinase, which seems to play a key role in BAT activity. Obviously, molecular cloning of this enzyme will be of great significance.

\section{REFERENCES}

Aquila, H., Link, T. A. \& Klingenberg, M. (1985). EMBO Journal 4, 2369-2376.

Aquila, H., Misra, D., Eulitz, M. \& Klingenberg, M. (1982). Hoppe-Seyler's Zeitschrift fur Physiologische Chemie 363, 345-349.

Arch, J. R. S., Ainsworth, A. T., Cawthorne, M. A., Piercy, V., Sennit, M. V., Thody, V. E., Wilson, C. \& Wilson, S. (1984). Nature 309, 163-165.

Bouillaud, F., Raimbault, S., Casteilla, L., Cassard, A.-M. \& Ricquier, D. (1988a). In Mitochondrial Carriers of Anions [L. Wojtczak and A. Azzi, editors]. Berlin: Springer Verlag.

Bouillaud, F., Ricquier, D., Thibault, J. \& Weissenbach, J. (1985). Praceedings of the National Academy of Sciences, USA 82, 445-448.

Bouillaud, F., Villarroya, F., Hentz, E., Raimbault, S., Cassard, A.-M. \& Ricquier, D. (1988b). Clinical Science 75, 21-27.

Bouillaud, F., Weissenbach, J. \& Ricquier, D. (1986). Journal of Biological Chemistry 261, 1487-1490.

Carneheim, C., Nedergaard, J. \& Cannon, B. (1984). American Journal of Physiology 246, E327-E333.

Cassard, A.-M., Bouillaud, F., Casteilla, L., Hentz, E., Raimbault, S., Villarroya, F. \& Ricquier, D. (1988). In Obesity in Europe 1 [P. Bjorntorp and S. Rossner, editors]. London: John Libbey.

Casteilla, L., Champigny, O., Bouillaud, F., Robelin, J. \& Ricquier, D. (1989a). Biochemical Journal 257, $665-671$.

Casteilla, L., Bouillaud, F., Forest, C. \& Ricquier, D. (1989b). Nucleic Acids Research 17, 2131. 
Himms-Hagen, J. (1985). Annual Review of Nutrition 5, 69-94.

Jacobsson, A., Nedergaard, J. \& Cannon, B. (1986). Bioscience Reports 6, 621-631.

Jacobsson, A., Stadler, G., Glotzer, M. A. \& Kozak, L. P. (1985). Journal of Biological Chemistry 260, 16250-16254.

Ricquier, D., Bouillaud, F., Toumelin, P., Mory, G., Bazin, R., Arch, J. \& Pénicaud, L. (1986). Journal of Biological Chemistry 261, 13905-13910.

Ricquier, D., Mory, G., Bouillaud, F., Thibault, J. \& Weissenbach, J. (1984). FEBS Letters 178, $240-244$.

Ridley, R. G., Patel, H. V., Gerber, G. E., Morton, R. C. \& Freeman, K. B. (1986). Nucleic Acids Research 14, 4025-4035.

Rothwell, N. J. \& Stock, M. J. (1979). Nature 281, 31-35.

Runswick, R. J., Powell, S. J., Nyren, P. \& Walker, J. E. (1987). EMBO Journal 6, 1367-1373.

Silva, J. E. \& Larsen, P. R. (1983). Nature 305, 712-713.

Trayhurn, P. (1986). In Brown Adipose Tissue, pp. 299-338 [P. Trayhurn and D. G. Nicholls, editors]. London: Edward Arnold. 